\title{
Implementation of Watershed Based Image Segmentation Algorithm using Distance Transform for Grid Computing Megha Sharma ${ }^{1}$, Seema Verma ${ }^{2}$ Banasthali University, Banasthali, India Email: meghasharma0110@gmail.com
}

\section{Abstract-}

A new method for image segmentation using watershed transform algorithm is presented in this paper. It takes advantage of the fact that the proposed algorithm produced good results even if the same parameters are used for the standard segmentation algorithm. The proposed segmentation algorithm will be very effective for grid computing as it seems to possess specific tasks of image information and detection in order to obtain a detailed and accurate image analysis.

Index Terms- Grid computing, Image segmentation, Watershed algorithm.

\section{Council for Innovative Research}

Peer Review Research Publishing System

Journal: INTERNATIONAL JOURNAL OF COMPUTERS \& TECHNOLOGY

Vol 10, No 6

editor@cirworld.com

www.cirworld.com, member.cirworld.com 


\section{INTRODUCTION}

Image segmentation [1-2] is an essential process for computer vision and for image analysis tasks. The general segmentation problem involves the partitioning a given image into a number of homogeneous segments, such that the union of any two neighboring segments yields a heterogeneous segment. Various methods are there for dealing with segmentation and feature extraction like, histogram based techniques, edge-based techniques, region based techniques, Markov random field based techniques, and so on. However, because of the variety and complexity of images, the segmentation is a challenging task.

Image segmentation analysis computationally requires large amounts of processing power for sharing any algorithm and there solutions. One way of obtaining this processing power is to make use of grid computing [3-4]. With grid computing we have the ability to distribute jobs to many smaller server components. The main advantage of grid computing is instead of having one heavily burdened server the load can be distributed across many computers, where the distributed nature of grid computing is transparent to the user. When a user submits a job they don't have to think about which machine their job is going to get executed on. The "grid software" will perform the necessary calculations and decide where to send the job based on policies.

Among the various image segmentation techniques, a well-known image segmentation technique is watershed transform using distance transform [5-6], which is based on mathematical morphology. In contrast to classical area based segmentation, the watershed transform is executed on the gradient image. A good number of works has already been carried out on watershed segmentation and these are available in the published or online literature [7-15]. In this paper we propose a new reliable algorithm for image segmentation using watershed using distance transform with image contrast enhancement concept which will found to be very useful for the grid computing environment.

This paper is organized as the following. The section 2 is a brief description of Grid technology. The section 3 introduces the morphological watershed method in image segmentation. Section 4 describes the proposed algorithm. The implementation results and discussions are described in section 5 and finally conclusions are discussed in section 6 . Experimental results presented in this paper are obtained by using MATLAB.

\section{THE GRID TECHNOLOGY}

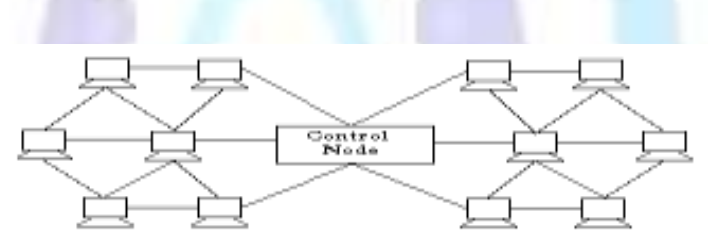

Figure 1: A basic grid computing system, every computer can access the resources of every other computer belonging to the network.

Sharing any algorithms and there solutions is a vast challenge. A grid is a network of computers. Grid technology is based upon so-called nodes that are linked together and share certain communication rules in using open standards. Grid computing framework allows a platform independent access to remote computing services. Web services allow end-users to fully interact with data, information requests as well as applications with a low level of user interaction. It is an Internet embedded network with variety of connected nodes which correspond to servers. Grids are the platform of communication standards, and users can freely concentrate on their desired tasks. Grid also provides network computing of the user's tasks, which is distributed computing. Grid provides a verity of services like, computational services, data services, application services, information services, knowledge services, etc.

\section{THE WATERSHED}

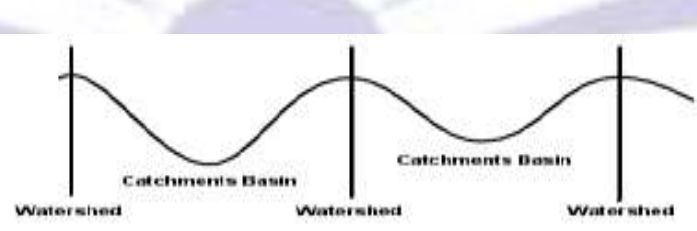

Figure 2: Watershed segmentation-local minima yield catchment basins; local maxima define the watershed lines.

The Watershed method or the watershed transform is an image segmentation technique based on gray-scale mathematical morphology. It can be classified as a region-based segmentation approach where the main idea behind this method comes from geography. If a landscape or topographic relief which is flooded by water, the divide lines of the domains of attraction of rain falling over the region forms watersheds. An alternative approach is to imagine the landscape being immersed in a lake, with holes pierced in local minima also called catchment basins (CB), will fill up with water starting at these local minima, and, at points where water coming from different basins would meet, dams are built. When the water level has reached the highest peak in the landscape, the process is stopped. As a result, the landscape is partitioned into regions or basins separated by dams, called watershed lines or simply watersheds. 


\section{A. THE MATHEMATICAL FORMULATION RELATED TO WATERSHED}

Let $f \in C(D)$ have minima $\left\{m_{k}\right\}_{k \in I}$, for some index set I. The catchment basin $C B\left(m_{i}\right)$ of a minimum mi is defined as the set of points $x \in D$ which are topographically closer to mj than to any other regional minimum $\mathrm{mj}$ :

$C B\left(m_{i}\right)=\left\{x \in D \mid \forall j\left[\left(l_{i}: f\left(m_{i}\right)+T_{f}\left(x, m_{i}\right)<f\left(m_{j}\right)+T_{f}\left(x, m_{i}\right)\right\}\right.\right.$

The watershed of $f$ is the set of points which do not belong to any catchment basin:

Watershed $(f)=D \cap\left(\bigcup_{i \in I} C B\left(m_{i}\right)\right)^{c}$

Let $\mathrm{W}$ be some label, $W \notin I$ The watershed transform of $\mathrm{f}$ is a mapping $\lambda: D \rightarrow I \cup\{W\}$, such that :

$\lambda(\mathrm{p})=\mathrm{i}$ if $\mathrm{p} \in C B\left(m_{i}\right)$.

And $\lambda(p)=$ if $p \in$ Watershed $(f)$

So the watershed transform of $f$ assigns labels to the points of $D$, such that (i) different catchment basins are uniquely labeled, and (ii) a special label $\mathrm{W}$ is assigned to all points of the watershed of $\mathrm{f}$.

\section{B. WATERSHED WITH DISTANCE TRANSFORM}

For digital image segmentation, the distance transform method is commonly used in conjunction with the watershed transform. The distance transform is the distance from every pixel to the nearest pixel of a binary image. In distance transform method every 1 -valued pixel has a distance transform value of 0 because its closest nonzero pixel is itself. In below, figure 3(a) shows a binary image matrix, and in figure 3(b) shows the corresponding distance transform.

\begin{tabular}{|l|l|l|l|l|}
\hline 1 & 1 & 0 & 0 & 0 \\
\hline 1 & 1 & 0 & 0 & 0 \\
\hline 0 & 0 & 0 & 0 & 0 \\
\hline 0 & 1 & 1 & 1 & 0 \\
\hline
\end{tabular}

(a)

\begin{tabular}{|l|l|l|l|l|}
\hline 0.00 & 0.00 & 1.00 & 2.00 & 3.00 \\
\hline 0.00 & 0.00 & 1.00 & 2.00 & 3.00 \\
\hline 1.00 & 1.00 & 1.41 & 2.00 & 2.24 \\
\hline 1.41 & 1.00 & 1.00 & 1.00 & 1.41 \\
\hline 1.00 & 0.00 & 0.00 & 0.00 & 1.00 \\
\hline
\end{tabular}

(b)

Figure 3: (a) shows a binary image matrix, and (b) shows the corresponding distance transform

\section{THE PROPOSED SEGMENTATION APPROACH}

In proposed approach one color image is chosen and converted in to gray scale. The next steps are to enhance the contrast of the grayscale image and obtaining the gradient image using canny operator. In fourth step the complement image has been obtained from the gradient image and finally the segmented image has been acquired by applying watershed algorithm using distance transform. The flowchart of the proposed algorithm is shown below.

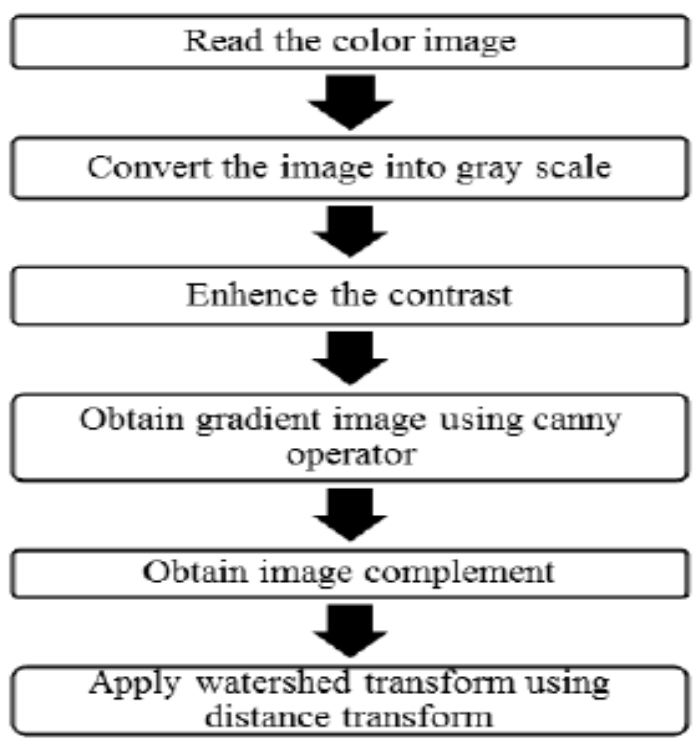




\section{RESULTS AND DISCUSSIONS}

In the present study two color images has been chosen. The first image is the most popular image in the recent literature, the 512 by 512 lina image and the second one is the image of Fruits having 299 by 215 dimensions which have been shown in figure 4(a), 5(a) respectively. The segmented images obtained by the standard watershed algorithm using distance transform are shown in figure 4(b) and 5(b) respectively. And again the segmented images obtained by applying proposed have been sown in figure 4(c) and 5(c) respectively.

It has been observed that the watershed lines in segmented images obtained by proposed algorithm are very sharp, thin and prominent. These segmented images are expected to create much more response clarity and sharpness of the edges and counters. The entropy and PSNR of the final segmented images applying standard watershed algorithm using distance transform and by applying proposed algorithm have been calculated and the values have been shown in the table 1.
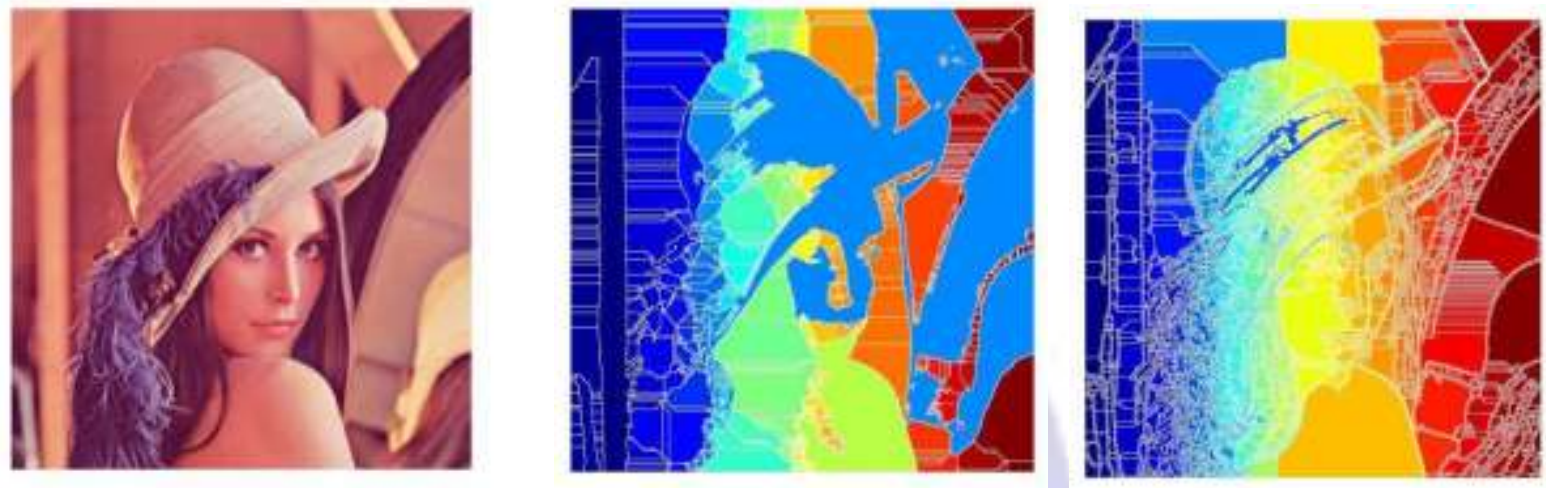

Figure 4: (a) Original image of Lena, (b) segmented image of Lina by applying watershed algorithm using distance transform, (c) segmented image of Lena by applying proposed algorithm.
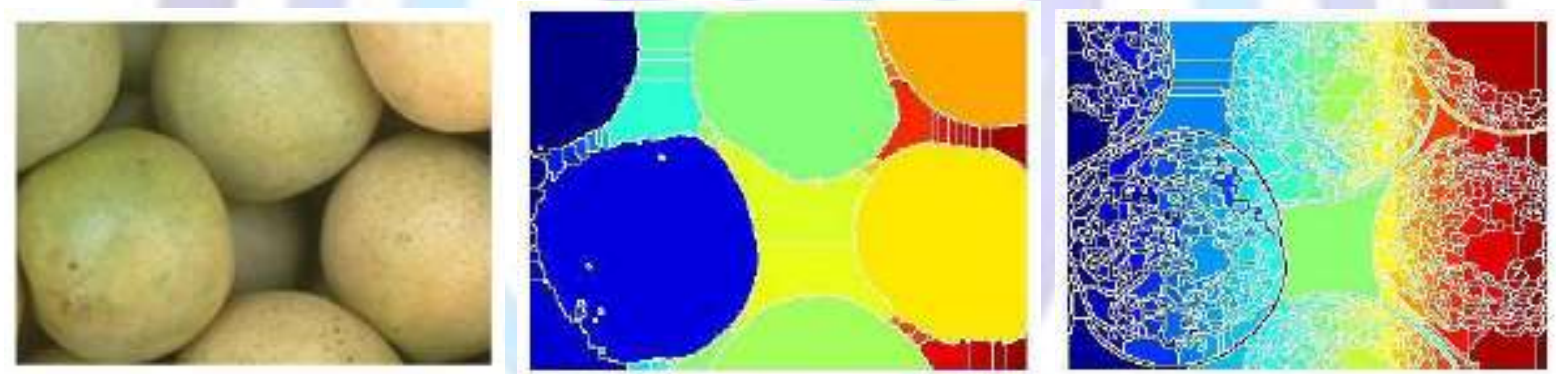

Figure 5: (a) Original image of Fruits, (b) segmented image of Fruits by applying watershed algorithm using distance transform, (c) segmented image of Fruits by applying proposed algorithm.

Table I- statistical measurement

\begin{tabular}{|c|c|c|c|}
\hline Image & Techniques & Entropy & PSNR \\
\hline Lena & $\begin{array}{c}\text { watershed algorithm } \\
\text { using distance transform }\end{array}$ & 4.7330 & 8.7199 \\
\hline Lena & Proposed algorithm & 5.0482 & 8.0373 \\
\hline Fruits & $\begin{array}{c}\text { watershed algorithm } \\
\text { using distance transform }\end{array}$ & 3.4212 & 7.9364 \\
\hline Fruits & Proposed algorithm & 4.0951 & 8.2148 \\
& & & \\
\hline
\end{tabular}




\section{CONCLUSION}

In this paper a new method for image segmentation had been presented. This method makes use of the observation that image segmentation results using watershed algorithm with distance transform with the concept of image contrast enhancement is a good form of segmentation technique. The statistical measurement analysis assures the effectiveness of the proposed algorithm. This algorithm will be very effective in a grid computing environment where the load will be on remote machines rather than clients with minimum processing power and better performance for image segmentation as grid computing is cooperation of different computers, for a specific job.

\section{REFERENCES}

[1] K. Haris,"Hybrid image segmentation using watersheds and fast region merging," IEEE Trans Image Processing, 7(12), pp. 1684-1699, 1998.

[2] Vicent L. Solille P, Watershed in digital spaces, "An efficient algorithm based immersion simulations", IEEE Transections PAMI, pp. 538-598, 1991.

[3] Kayser K, Molnar B, Weinstein RS: Virtual Microscopy - Fundamentals -Applications - Perspectives of Electronic Tissue - based Diagnosis. VSV Interdisciplinary Medical Publishing; 2006.

[4] Thomason MG, et al: Simulation of emission tomography using grid middleware for distributed computing. Comput Methods Programs Biomed 2004, 75(3):251-8.

[5] S. Beucher, "The Watershed Transformation Applied To Image Segmentation", Centre De Morphologie Mathématique. Ecole Des Mines De Paris, 1991.

[6] Shameem Akthar, D. RajyaLakshmi , Syed Abdul Sattar, "Suppression of Over Segmentation in Watershed Transform Using Pre Processing Method", International Journal of Computer Technology and Electronics Engineering, Volume 2, Issue 2, April 2012.

[7] S. Beucher, "Watershed, hierarchical segmentation and water fall algorithm," in Mathematical Morphology and Its Applications to Image Processing, Dordrecht, The Netherlands: Kluwer, 1994, pp. 69-76.

[8] Beucher, S., and Meyer, F. The morphological approach to segmentation: the watershed transformation. In Mathematical Morphology in Image Processing, E. R. Dougherty, Ed. Marcel Dekker, New York, ch. 12, pp. 433-481, 1993.

[9] F. Meyer, S. Beucher, "Morphological Segmentation," Journal of Visual Communication and Image Representation,vol. 1, pp. 21-46, 1990.

[10] Gonzalez \& Woods, Digital Image Processing, 3rd edition, Prentice Hall India, 2008.

[11] K. Haris,"Hybrid image segmentation using watersheds and fast region merging," IEEE Trans Image Processing, 7(12), pp. 1684-1699, 1998.

[12] S. Thilagamani, N.Shanthi, "A Novel Recursive Clustering Algorithm for Image Oversegmentation", European Journal of Scientific Research, Vol.52, No.3, pp.430-436, 2011.

[13] Peter Eggleston, "Understanding Oversegmentation and Region Merging", Vision Systems Design, December 1, 1998.

[14] S. Beucher, "The Watershed Transformation Applied To Image Segmentation", Centre De Morphologie Mathématique. Ecole Des Mines De Paris, 1991.

[15] Shameem Akthar, D. RajyaLakshmi , Syed Abdul Sattar, "Suppression of Over Segmentation in Watershed Transform Using Pre Processing Method", International Journal of Computer Technology and Electronics Engineering, Volume 2, Issue 2, April 2012. 